\title{
Digital knowing and digital making in network and fab labs an intersection between culture and education
}

\begin{abstract}
The paper proposes a reflexion on the innovations that characterize the ongoing transformation in the contemporary society context and on the challenges that educative institutions have to front. In particular, we will focus on some twists among possible educative scenarios and social and cultural contexts, identified through the characteristics of openness, participation and networking. These characteristics will be recalled referring to the cultural setting, to new knowledge and economic-productive models, always with a sight to the connections between technological innovation and education. Within this frame, the paper recalls the Fab Lab educative model-and some other lab experiences created to promote networking -intended as expression of the intersection between the connective value of the net and the radical innovation of digital making. The didactic practise characterizing this model promotes the educative and pedagogical tradition of the laboratory by incorporating the value of the internet culture and its potentiality, and becomes expression of a dynamic that, in school and in university classrooms, put together the cultural technological characteristics and the technical development that take shape on the new social and instances.
\end{abstract}

Keywords: openness, digital culture, fablab, entrepreneurship
Volume 2 Issue 6 - 2018

\author{
Annalisa Buffardi \\ National Institute for Documentation and Innovation in \\ Education (INDIRE), Italy
}

Correspondence: Annalisa Buffardi, National Institute for Documentation and Innovation in Education (INDIRE), Italy, Email a.buffardi@indire.it

Received: August 20, 2018 | Published: December 27, 2018

\section{Introduction}

This paper proposes a reflexion on the innovations that happen during the spread of digital systems in the contemporary society context and on the challenges that educative institutions have to front The ongoing transformation will be examined starting by openness dynamics, connectivity and collaboration, characterizing the web culture. In particular, we will focus on some twists among possible educative scenarios and social and cultural contexts. These scenarios seem to be identified through the characteristics of participation and networking. By looking to productive changes, they expand their competencies also to the capacity to "anticipate innovation" and to transform creative ideas in original solutions, services and products for social wealth and economic development. These characteristics will be recalled referring to the cultural setting, to new knowledge and economic-productive models, always with a sight to the connections between technological innovation and education.

Initially, the promises and the challenges of participation of the network society will be introduced, as well as the role of the educative system towards the internet potentialities and the new divide generated. Then, some models will be recalled. Those models that in the setting we are considering, are based on the principle of accessibility, of sharing, and on the network logic. In particular, the models of open knowledge and of open innovation, expression of the internet culture, constitute the reference framework. Having these as starting point, and referring to the new scenarios made possible by technologies, the following paragraph links the public participation instances with the new availability of access to information, data, scientific research, and to techniques and production technologies. A scenario that suggests an easier participation both to public debate and to the definition of the paths of change. A scenario in which the new availability and the easier access to technologies and knowledge seem to increase the possibilities to the choices and to the construction of the "world we want". It is a theme that recalls new opportunities and new divides among who is capable to participate to the vision of change and who is excluded, and involve the role of the educative system in the developing of the necessary competencies to participate to the contemporary society challenges.

Within this frame, the last paragraph recalls the Network and Fab Labs educative model, and it starts from the first Gershenfeld's vision who believes that this experience is the expression of the intersection between the connective value of the net and the radical innovation of digital making. The model, in its different declination, performs the creative making, and takes shape on "imagination, passion and art", as in the tradition of the scientific laboratory, ${ }^{1}$ and it leads to innovation through the passionate activity of "hands and minds deeply imbued" (cfr.ivi, p.42). Different forms of the model are for example the FabLab@School version, that gives value to the pedagogical side, or the Italian version of Contamination Lab, that underlines the role of the research and of the disciplinary and sectorial contamination. The didactic practice characterizing this model promotes the educative and pedagogical tradition of the laboratory by incorporating the value of the internet culture and its potentiality, and becomes expression of a dynamic that, in school and in university classrooms, put together the cultural technological characteristics and the technical development that take shape on the new social instances.

\section{Opening, networking, participation and the new inclusion gaps}

The diffusion of what has been called, with a criticized expression, web 2.0, inaugurates a new web phase, in which the participation, the interaction, the users involvement, the forms of connective intelligence and the sharing of the thinking processes become evident. 
Various researchers have underlined as the logic of the network is linked to a new way of producing, communicating, managing and living, ${ }^{2}$ through the diffusion of new thinking modalities, that are defined within logic of connection with the others, ${ }^{3}$ sustained by an easier circulation of ideas, information and knowledge, ${ }^{4}$ creating forms of sharing and online spontaneous affiliation. ${ }^{5}$ The more and more availability of technologies also for the material production has conducted in a parallel way to that one that Gershenfeld ${ }^{6}$ has defined "democratization of the production processes". In the fourth industrial revolution, characterized by new instruments (such as 3D printers), by open source processes and by the use of the huge amount of data available today, the economy add value to the role of knowledge, of the ideas, of the research and of the human capital in the processes of productive development. The increasingly common availability of technologies for the production, associated with the logic of the network, draws possible sceneries that in combining the connective value of the net with the radical innovation of the production, give value to the participation, creativity, and innovation. On these foundations, they push towards the entrepreneurial skill of the young, risking however to propose again paralyzing rhetoric and to create new gaps. It is an example the definition of "native digitals" that with its determinist implications ${ }^{7}$ has obscured the challenge value of the educative, informative and participative potential of the digital media. ${ }^{8}$ In the same way, as Bennet and Segerberg underline, beyond the proclamation on the democratic and participative power of the digital media, "we are concerned that the organizational logic and underlying dynamic of connective action is not well established. Understanding how connective action engages or fails to engage diverse populations constitutes part of the analytical challenge ahead".

Similarly, in the economic and employment area, the recent wide public debate on youth entrepreneurship risks to "unfairly shift much of the responsibility for job creation and labour market performance away from the larger public and private sectors to young people, which can leave many youth vulnerable" (United Nations, 2016, p.2). The ongoing transformations involve the educative system on more levels. The first and main matter with which it has to compare is relative to the various and wider possibility to access to the knowledge and to new educative processes. Another and discussed aspect regards the integration between digital and traditional tools, the transformation of didactic settings and learning settings by using technologies also in face-to-face learning. On another level, it is necessary to consider the "educational and training needs based upon an understanding of evolving skills demands driven by technological change" and "the ways in which technology can be best used to prepare, train and retrain the future workforce". ${ }^{9}$

Taking into account the participative potentiality of digital media, the first reflection is the need of public and education policies to promote, above all, a wider digital inclusion. In this setting, as Livingstone \& Helpser ${ }^{10}$ say, the crucial matter is the different use of the internet, and as a consequence the practical skill required to maximize the benefits of internet use. ${ }^{10,11}$ Within the frame of political knowledge as a critical resource associated with power and inclusion, Wei \& Hindman ${ }^{11}$ examine the relationship between the digital divide and the knowledge gap, pointing out that "the differential use of the Internet is associated with a greater knowledge gap than that of the traditional media" (ivi, p.217). In the different areas in which the educative system is called to compare itself to the ongoing dynamics, the characteristics of the digital technologies and of the net settings convey cultural changings that represent the range of the challenge. The easier access to knowledge, data and digital production technologies opens to scenarios in which the logic of connective thinking is translated into call creative connecting making. A perspective that proposes again the main characteristics of the internet culture.

\section{The internet culture and the models of open knowledge and of open innovation}

The openness of the Internet's architecture was the source of its main strength. ${ }^{2}$ It represents the starting point to observe the dynamics relating to the relationship between the use of technologies and the emergence of new social, economic and cultural scenery. Openness and participation reflect the internet culture and according to some researcher. ${ }^{5,8,12,13}$ they try to pass the gap between educative institutions and daily life especially in young people.

Nowadays, we are in a phase in which the diffusion of the social media has spread "the hacker ethic". Himanen ${ }^{14}$ intended as culture of sharing, of participation, of collaboration - to a wider community of users thus having a great impact in the different social life settings. The actual phase of technological maturation through the diffusion among the users of the social networking sites can express and reflect the intentions of the founding founders of the web, according to whom this instrument should have promote the intercreativity and the collaboration "mind-to-mind" to work together, to create with other, to make together or to solve problems together. ${ }^{15}$

In this way, the Open Access approach-based on the sharing information, on free exchange and on peer-to-peer-collaboration represents one of the main innovations that has defined the principle of openness and freedom of the web. It is also one of the main cultural instances in contemporary educative policy challenges. "The Open Educational Resource movement seems to realize the promises made 30 years before the invention of the web regarding a free and open education contributing to the realization of the traditional ambition of a wide public school". ${ }^{13}$ The negotiation process of this experience in the context of the wider educative system seems still ongoing. As underlined also in the National Academy of Science report," "this model of online education is still young". To the ongoing challenge that regards the incorporation of technology into the didactic, belongs also the way in which the background of the open educational resources (also MOOC definitions) will appear in the school system. Actually anyway, "there is evidence that online courses benefit most those students who already have well-developed learning skills and a strong educational background, and may leave students already behind in education even further behind". Evidence that reinforces the necessity that the educative system, in particular regarding the primary and secondary instruction levels has to take charge of the challenge to promote among young people adequate digital competences to realize the web promise. This promise stretches from the characteristics and potentiality of the net and still exists for the development.

Also regarding the economic-productive side, the category of openness represents the dynamics of ongoing mutation and expresses the dimension of co-project and co-construction (regarding ideas, knowledges, and projects). Already Castells ${ }^{2}$ showed that, in the network society, the information is considered "raw material", a key resource in the economic development. In 2006 Yochai Benkler, underlined the passage from the free market economy to the free exchange economy in the new model defined Commons-based peer production or social production. According to the researcher, one of the main innovations linked to the Internet development is the 
diffusion of an economic model whose configuration is based on open access principles, the open source, free software, and peer to peer principles. The "networked information economy", as revealed by the researcher, is based on technological and cultural changes, allowing an enhanced interlinkage among peer and adding value to the production of information and culture. The "combination of new ideas "as a facilitator of growth and innovation is revealed, among the others, also by Brynyolfsson \& McAfee, ${ }^{16}$ according to whom the interlinkage among individuals produces an economic development and the participation of the users is possible thanks to technological innovations which are able to generate productivity and competitiveness. As Brynyolfsson and McAfee underlined, practical examples of recombining innovation are given by models of open innovation and crowdsourcing. They show, both in the scientific and productive settings, how it is possible to produce through technologies and through the involvement of more individuals, reaching a result, solving a problem, giving a definition or developing a product.

In Chesbrough ${ }^{17}$ in defining the open innovation paradigm, observed the possibility and the necessity for companies to turn also to external ideas to improve their technological competences and the access to new markets through a new approach based on a new vision of knowledge and on a different logic on the use of sources and ideas. ${ }^{17}$ This vision is linked to the widespread access to technologies for digital production and leads to a scenario in which the new ideas, circulating in the open debate can be easier realized, and create innovative solutions, resulting in "new manufactures". In Chris Anderson's words,$^{18}$ enlightened and enthusiastic observer of processes that are associated with Internet diffusion, we are going more and more toward an entrepreneurship and an ever faster innovation, with constantly decreasing barriers. It is a system based on small well linked companies, in which anyone stimulates the other to produce a micro- productivity setting that can quickly answer to the market and with a few fixed costs. It is a setting characterized by a billion of small business opportunities that can be discovered and put to great use by intelligent and creative people. The essence of culture of participation and potential of intercreativity is incorporated in these practices. An essence should be searched also in the use of technologies in the daily school practises.

\section{Science, technology and entrepreneurship for the world we want}

In discussing the social dynamics of public participation in the new century, we can't ignore the role of scientific and technologic acceleration, inheritance of the last decades of the twentieth century that has led to a transformation of the relationship between science and technology having an even more evident impact in our daily life. From eighties on, the new Big Science, even more social and economic enterprise that needs loans and public agreement, finds itself daily on negotiating its relevance and social acceptability with a pluralism of audience and contexts. As Bucchi remembers, ${ }^{19}$ various forms of public mobilisation emerged in relation to specific scientific and technological matters and, in general, to the growing preoccupation regarding the unexpected and undesired consequences of scientific and technological development for the environment, or for the citizens' health. Thus leading to the progressive recognition of the participation of citizens' group to decisional processes in these settings.

The diffusion of web 2.0 carries and sustains the challenge towards an active and proactive public participation. The hacker ethic- in the words of de Kerckhove. ${ }^{20}$ Buffardi et al. ${ }^{20}$ is one of these springs of "the world we want". The true challenge today is the participation to the global discourse about what is necessary to do, an assumption of responsibilities. This, for example, is evident in the ecologic setting: the assumption of responsibility towards the destiny of our world". The public involvement today seems to meet new manifestations of progress. The dynamics of ongoing transformation explicitly and clearly recall the innovation boost, generic category to which we refer to as an alignment with the instances of contemporary society, also at a development of political level. The ability of innovation is recognized, for example, by European politics as basic to a productive and economic relaunch that in the European strategy of 2020 tends to an "intelligent growth" that is based on knowledge and innovation.

The push toward innovation leads to the adoption of new definitions that go through the social, cultural, economic and, entrepreneurial settings. It is the case, for example, of the Green Economy that, in the wake of the ecologic culture and driven by the new technological possibilities, involves traditional sectors such as agriculture. The concept of "quality of life", affirmed in the sixties and seventies in relation to the awareness that wealth and social development cannot be the tout court result of the economic growth, today seems to find an operational application in the new models linked to the concept of Smart City. In recognizing the need for adjustment to the requirements of man and to wealth culture, the same technologies became "smart technologies".

A transition that fits in, and is reflected in opportunities, and pushes for a new entrepreneur in which creativity, technology, knowledge and innovation are deeply linked. In the context of dissemination of 2.0 web, of user-generated content and of digital making, the culture of participation opens scenarios that makes possible expressing opinions, favourable or contrary positions, or promoting mobilizations of public consensus-dissent.

This scenario allows us to think and to plan solutions, products and services to better meet the contemporary changing needs. A scenario in which "The world we want", the world we would like to create ${ }^{21}$ is generally open to creative and participative possibilities of anyone has the conscious access to technologies and knowledge, of anyone has the opportunity to identify possible choices for their life path. "Understanding the entrepreneurship" in younger people, as Strano observes, ${ }^{22}$ with reference to the capability approach, means in educative and formative contexts, to individuate the ways to an expansion of areas of freedom and of individual agency, to go towards the promotion of innovation processes and, in the same time, towards an expansion of individual possibilities of ideation and realization of professional and life projects. "It is not only to qualify our students with technic competences, but also to approach a job culture capable of interpreting new paradigms of jobs and innovation inside an educative and formative dimension of our schools"(ivi,p.112). Understanding entrepreneurship means to shape in people the competences and the generative capacity for a widening of their freedom spaces, for a strengthening of the capacity to see their future and to express with concrete choices their directionality knowing how to understand among the different opportunities the most valuable ones. Understanding entrepreneurship means to collocate strategically in segments of connexion between a world of formation and a world of work, requalifying paths of learning through the planning of formative architectures capable to integrate different 
contexts, and to reinforce the dialogue among universities, enterprises and institutions, defining in this way new pedagogical models based on multidisciplinary competent and generative actions.

\section{Net technologies and connective thinking in network and fab Labs model}

In the description of XXI century competencies, the European Union, the Organisation for Economic Co-operation and Development and various world organizations have defined the areas regarding the collaboration, creativity, innovation, problem solving as the ones needed to contribute and to participate in the challenges of contemporaneous society, ${ }^{23}$ to the personal growth of the citizens and to promote an economic growth based on knowledge and innovation. In the numerous definitions of competencies, as shown by Binkley et $\mathrm{al}^{24}$ we can reach a wide, complete and homogenous framework of knowledge, abilities and skills that contribute to define them. Regarding creativity and innovation, for example, the areas are described through elements such as "recognizing the fields of innovation", "developing innovative and creative ideas that can have an impact and be adopted", "work in a creative way with others, by implementing and communicating new ideas in an effective way". Competencies that widen the front of the public participation to the ability to recognize the sectors of innovation, planning, and developing original ideas to reply to the social exigencies, to transform creative ideas in products and services. From the same perspective close to the observation of new educative models to "the making of Young People Who Will Change the World", Tony Wagner wrote in 2013:25 "what we urgently need is a new engine of economic growth for the twentyfirst century. The solution to our economic and social challenges is the same creating a viable and sustainable economic that creates good jobs without polluting the planet. And there is general agreement as to what that new economy must be based on. One word: innovation". ${ }^{25}$

The "New Vision for Education", according to the World Economic Forum $^{26}$ looks at an "innovation driven economy" and pinpoints as central, together with basis literacy, an area of competencies such as the critic thought and the creativity, the communication and the collaboration and an area of "character qualities", among which curiosity, enterprising spirit, and leadership. These seem as the "human skills that artificial intelligence (AI) and machines see unable to replicate", as detected in the recent large scale canvassing of technologists, scholars, practitioners, strategic thinkers and education leaders, made by Pew Research Center and Elon's Imagining the Internet Center. Many experts surveyed claim that "these should be the skills developed and nurtured by education and training programs to prepare people to work successfully alongside AI. They suggest that workers of the future will learn to deeply cultivate and exploit creativity, collaborative activity, abstract and systems thinking, complex communication, and the ability to thrive in diverse environments". In the words of the Simon Gottschalk, sociologist at the University of Nevada, respondent to the investigation, these also include the ability to efficiently network, creativity and critical thinking. ${ }^{27}$ As we can read in the report, other respondents mentioned traits including leadership, design thinking, and the capacity to motivate, mobilize and innovate. Jonathan Grudin, principal researcher at Microsoft, commented: "People will create the jobs of the future, not simply train for them, and technology is already central. It will undoubtedly play a greater role in the years ahead" (ivi).The digital and entrepreneurial competencies have, in this context a particular relevance.

The digital competence is formed, as synthesized in the European framework DIGCOMP, in knowledge, abilities and attitudes necessary to use technologies and through them, to realize activities, solve problems also with original solutions, communicate, collaborate, manage information, create, sharing, and build knowledge. ${ }^{28}$ The framework 2016 update reinforces moreover the concept in the direction of how to use digital technologies in a creative way to create a new knowledge, and innovate processes and products. ${ }^{29}$ In this sense, it recalls the level, definite as "digital transformation", in which we are able to use the digital opportunities for innovation and improvement, thanks to their creative use. The digital transformation is seen as central for the development of a culture of innovation and creativity", as we can read in the Agid guidelines for digital competencies. ${ }^{30}$ Regarding the entrepreneurial competencies, they always seem more relevant in the programmatic indications of the different national governments and of the European Union, from the context of the rapid changes linked to our complex knowledge-based economy and society and in view of the goal that is to potentiate the productive competitiveness to react to the economic crisis and to the generalised unemployment. ${ }^{31}$ From the definition of key competencies in 2006 to the European framework Entre Comp of 2016, the creativity, the ability of innovation, of transforming the ideas in actions, of assuming risks, represent constitutive elements, in a frame that enriches itself from the capacity of "Spotting opportunities" and to answer to the challenge of change; of "Vision", intended as predisposition to imagine a desirable future and to use this vision to guide change processes; "Motivation and Perseverance" processes; "Ethical and sustainable thinking" processes. ${ }^{32}$

The education to entrepreneurship is promoted at all instructional levels, from the primary school to post graduate training and is seen as "long life and work" competence. The competence is seen as the application of creative ideas for practical situations and less defined through severe business-oriented principles. It has the aim to create understanding mentalities to answer to opportunities, exigencies and challenges. It recalls the areas of problem solving, group work, communication, and creativity.(ivi, pp.21-23).

As Bilkstein argues 33 "every few decades or centuries, a new set of skills and intellectual activities become crucial for work, conviviality, and citizenship, often democratizing tasks and skills previously accessible to experts (...) Today, there are calls everywhere for educational approaches that foster creativity and inventiveness. (...) Simultaneously, digital fabrication technology became better and more accessible, and the intellectual activities enabled by the new technology became more valued and important". The Fab Lab model, and all experiences created to promote networking, starting from a major accessibility of technologies for the production, represents an educative scenario that takes its form on the creative potential of new technologies, in its different declination on various educational levels. The FabLab represent a development of the researches and of the courses made by Neil Gershelfed at Mit since 1998, a program suggestively defined "How to Make (almost) anything". A Fab Lab is a low-cost digital workshop equipped with laser-cutters, routers, 3D scanners, 3D milling machines, and programming tools. The discriminant element however is the intersection of digital computing and communications with digital fabrication. The digital processes, the network value, on which the FabLab are based on, make available "a more of the planet's brainpower" (Gershenfeld in Chandler 2016). "Fab Lab are a net, just as internet is. They generate business, activities and creations that share knowledge and projects. What is important is creating through the code the same materials till touching the 
processes and the social organization". (Gershenfeld in D'Alessandro, 2016). ${ }^{34-36}$

Starting from the concept of FabLab introduced by Gershenfeld, in 2009 Blikstein launched by Stanford University theFabLab@School, a new type of digital fabrication lab especially designed for school and children. Such labs are a place for invention, creation, discovery and sharing, learning environment planned around technology for design and construction such as 3D printers and laser cutters and robotics "into the hands of middle and high school students". They represent "a convivial environment in which students can concretize their ideas and projects with personal engagement".

Pedagogically, as Blikstein underlines, ${ }^{33}$ this model is not an innovation, as the importance of the relation between making and learning was already studied by Papert, and whose constructionist perspective represents the intellectual root of Fab Learn Labs. Starting from this frame, the origin of this model is the technology value "not only as a way to optimize the existing educational system, but as a transformative force that can generate radically new ways of knowing and learning". ${ }^{2}$ The model has among its aims, the promotion of creativity and innovation, the collaborative problem solving, and the capacity of learning to learn, by creating an authentic context for learning, that allows children to experiment, take risks, and play with their own ideas, giving them permission to create, imagine and build. The activities require the use of age-appropriate robotics, in the context of "a fully-developed research program, with custom-made impact measures and learning metrics especially designed for digital fabrication and project-based environments". ${ }^{37,38}$ In Gershenfeld's original version, addressed to university students and to adults, outside and inside the campus, the network value for the sharing and the shared development represents moreover an essential key element.

In Italy among the various educative level versions of the model, the Contamination $\mathrm{Lab}^{3}$ represents a university experience that introduces and gives value to the contamination element among the subjects, professional entrepreneurial, institutional, university and researching settings to develop innovative entrepreneurial projects. The promotion of "Territorial Lab for Employment" in upper secondary school goes in this direction. The Territorial Lab, realized in the schools with the collaboration of institutions and associations, universities, foundations, private entrepreneurships, are proposed as "spaces with a high innovative profile that are available to more schools in the territory where to develop advanced didactic practices together with local politics for the job and entrepreneurships (DM 657/2015). The Labs give value to strategic sectors of the made in Italy, relating to the territorial vocations, and are like a bridge between old professions and innovation practices. Starting from Labs of Digital Fabrication, these models indicate a path in which the educative systems take art to the ongoing transformations. A way that is building up actually, so it happens to other settings. As Gershenfeld says also at an economic level, the FabLab production model cannot yet "compete with the mass production (...). Nevertheless, also if local production doesn't

${ }^{1}$ https://tltl.stanford.edu/project/fablearn-labs

${ }^{2} \mathrm{https}$ ://tltl.stanford.edu/

${ }^{3}$ Contamination Lab were born in 2013 in the area of the call for applications Startup made by MIUR, in collaboration with the Mise, following that were financed four CLab; University of Naples Federico II; University of Catania; University Mediterranea in Reggio Calabria and University of Calabria. More CLab were born in others universities, such as University of Cagliari, Polytechnic of Marche, Cattolica of Milano, and University of the studies in Trento. substitute the serial ones, they will change the world".

In the same way, the educative scenarios that take their shape within the dimension of the creative Lab, based on the use of digital technologies of production and on the networking logics, can't compete with the yet prevalent fordist model, but represent an emergent model that incorporates the technologies and its culture. And that maybe, paraphrasing Gershenfeld, will end to change the school.

\section{Conclusion}

The Network and Fab Labs model- in its different declinationrepresents one of the forms through which is expressed the intersection between the values of the internet culture and some consolidates principles of the pedagogical tradition. This in the direction of one of the possible way of social development offered by the diffusion of network technologies. In these pages, the reflection on this experience has been introduced through the recall to the network logic and to the open source methods that enable the emergence of knowledge and production processes based on circulation and sharing of media, ideas, material and immaterial resources. In the educative setting, this model intercepts a vision of socio-cultural and economic change that is based on the openness principles and on promises of sustainability of progress, social innovation and wealth.

The vision that accompanies us in the fourth industrial revolution is the one of a democratization of production processes sustained by knowledge, research, and creativity. It is based on processes of sharing development and entrepreneurial spirit, that can lead to the realization of intelligent innovations able to meet the needs of communities, to personalize consumes and to democratize the production and development choices. The high value in terms of knowledge and research involves the educative system, and reinforces the terms of the challenge in relation to new divide.

The Network Labs are the way through which the educative system participates to the ongoing changes, by intercepting the dynamics and integrating the didactic practices, the values and the principles of the internet culture. This area is not new for school for what concerns the active didactic methods, cooperative learning, and teaching laboratory. As Baldacci ${ }^{36}$ underlines, by following some "DeWayne suggestions", "the laboratory is a didactic strategy: it has a role and a strategic relevance in school curriculum, as an indirect formation of the mind. It structures a context that has long term and second level effects on mindsets, creating the appropriate conditions for the reflexive thinking". In the contemporary context, the Network Labs express a cultural educative space embedded in the contemporary transformations that can create the appropriate conditions for the connective thinking.

\section{Acknowledgments}

None.

\section{Conflicts of interest}

The author declares there is no conflicts of interest.

\section{References}

1. Medawar PB. Is the Scientific Paper Fraudulent? Saturday Review. $1964 ; 1: 42-43$.

2. Castells M. The Internet Galaxy: Reflections on the Internet, Business and Society. USA: Oxford University Press; 2001. 
3. de Kerckhove D. Connected Intelligence. The Arrival of the Web Society. Toronto: Sommerville house; 1997. 224 p.

4. Benkler Y. The Wealth of Networks: How Social Production Transforms Markets and Freedom. New Haven, Conn: Yale University Press; 2006. $527 \mathrm{p}$.

5. Jenkins H. Confronting the Challenges of Participatory Culture: Media Education for the 21th Century. USA: The Mit Press; 2006.

6. Gershenfeld N. How to Make almost Anything. The Digital Fabrication Revolution. 2012. p. 91-96.

7. Buckingham D, Willet R. Digital generation. Children, Young People and New Media. Lawrence Erlbaum Associate; 2006; 31(5):706-707.

8. Livingstone S. Children and the Internet: Great Expectations, Challenging Realities. UK: Polity Press; 2009.

9. National Academy of Science. Information Technology and the U.S. Workforce: Where Are We and Where Do We Go from Here? USA: The National Academies Press; 2017.

10. Livingstone $\mathrm{S}$, Helpser E. Gradations in digital inclusion: children, young people and digital divide. New media \& society. 2007;9(4):671-696.

11. Wei L, Hindman DB. Does the Digital Divide Matter More? Comparing the Effect of New Media and Old Media Use on the Education-Based Knoweldge Gap. Mass Communication and Society. 2011;14(2):216-235.

12. Wiley D, Hilton J. Openness, Dynamic Specialization, and the Disaggregated Future of Higher Education. International Review of Research in Open and Distance Learning. 2009;10(5):768.

13. Deimann M, Friesen N. Exploring the Educational Potential of Open Educational Resources. E-Learning and Digital Media. 2013;10(2):112-115.

14. Himanen P. The Information Society and the Welfare State:The Finnish Model. USA: Oxford Scholarship Online; 2011.

15. Berners-Lee T. Weaving the Web. The Original Design and Ultimate Destiny of the World Wide Web by Its Inventor. USA: Harper; 1999.

16. Brynjolfsson E, McAfee A. The Second Machine Age. Work, progress and prosperity in a time of brilliant technologies. USA: WW Norton \& Company; 2014.

17. Chesbrough H. Open Innovation. The New Imperative for Creating and Profiting from Technology. USA: HBS Press; 2003.

18. Anderson C. Makers. Il ritorno dei produttori. Per una nuova rivoluzione industriale. Milano: Rizzoli. 2012. 311 p.

19. Bucchi M. Scienza e Società. Bologna: Il Mulino. 2002.

20. Buffardi A, de Kerckhove D. Education Overload, Nuove sfide per l'apprendimento. In: Savonardo L, editor. Bit Generation. Culture giovanili, creatività, social media. 2013. p. 85-99.
21. Kingwell M. The World We Want: Virtue, Vice, and the Good Citizen. 2001. 304 p.

22. Strano A. Capacitare entrepreneurship per l'attivazione professionale dei giovani. Formazione e Insegnamento. Rivista Internazionale di Scienze dell'Educazione e della Formazione. 2015;13(1):109-116.

23. Niemi H, Harju V, Vivitsou M, et al. Digital Storytelling for 21 st-Century Skills in Virtual Learning Environments. 2014;5(9):657-671.

24. Binkley M, Erstad O, Herman J, et al. Defining 21st century skills and assessments. In: Griffin P, McGaw B, editors. Assessment and Teaching of 21st Century Skills. 2010. p. 77-66.

25. Wagner T. Creating Innovators: the Making of Young People Who Will Change the World. USA. 2013.

26. WEF New Vision for Education, Unlocking the Potential of Technology. 2015. 32 p.

27. Raine L, Anderson J. The Future of Jobs and Jobs Training. Pew Internet Research Center; 2017.

28. Ferrari A. DIGCOMP: A Framework for Developing and Understanding Digital Competence in Europe. 2013. 50 p.

29. DIGCOMP. 2016.

30. Agid. Programma nazionale per la cultura, la formazione e le competenze digitali: Linee Guida. 2014. 164 p.

31. European Commission/EACEA/Eurydice. Entrepreneurship Education at School in Europe. Eurydice Report. 2016. 238 p.

32. Bacigalupo M, Kampylis P, Punie Y, et al. EntreComp: The Entrepreneurship Competence Framework. EUR 27939 EN. 2016. 39 p.

33. Blikstein P. Digital Fabrication and 'Making' in Education: The Democratization of Invention. In: Walter-Herrmann J, Büching C, editors. FabLabs: Of Machines, Makers and Inventors. Bielefeld: Transcript Publishers; 2013.

34. Chandler DL. 3 Questions: Neil Gershenfeld and the spread of Fab Labs. 2016.

35. D'Alessandro J. Tutti pazzi per i Makers. Neil Gershenfeld: La libertà del web rivive nel mondo reale. 2016

36. Baldacci M. Il Laboratorio come strategia didattica. Suggestioni deweyane. In: Filograssoe N, Traviglini R, editors. Dewey e l'educazione della mente. Milano: Franco Angeli; 2004. p. 86-95.

37. Bennet WL, Segerberg A. The logic of Connective Action. Journal of information, Communication \& Society. 2012;15(5):739-768.

38. United Nations. Youth Civic Engagement. World Youth Report. 2017. 